ELORE (ISSN 1456-3010), vol. 15 - 1/2008.

Julkaisija: Suomen Kansantietouden Tutkijain Seura ry.

[http://www.elore.fi/arkisto/1_08/aho1_08.pdf]

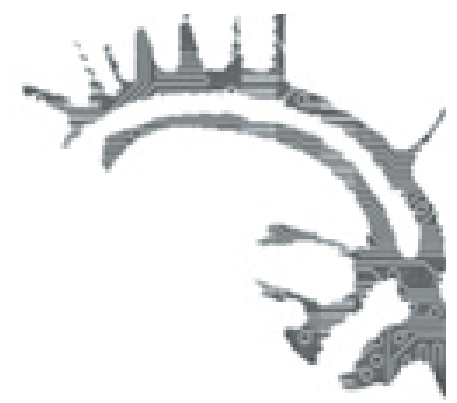

\title{
KIRJA-ARVIO: \\ KESKIAJAN LOPPU JA YKSI HULLU MYLLÄRI
}

Ginzburg, Carlo 2007: Juusto ja madot. 1500-luvun myllärin maailmankuva.

Helsinki: Gaudeamus. 280 sivua.

\section{$\underline{\text { Joonas Ahola }}$}

Juusto ja madot (italiankielinen alkuteos 1976) kertoo, kuinka omaperäinen itsenäisesti ajatteleva mylläri Domenico "Menocchio" Scandella joutuu Concordiassa Italiassa vuonna 1584 inkvisition hampaisiin. Perusteellisissa inkvisitiotutkimuksissa hän kertoo auliisti maailman ja Jumalan olemukseen liittyviä käsityksiään, jotka poikkeavat jyrkästi kirkon hyväksymistä:

Inkvisiittori: Ne enkelit, jotka sinusta ovat Jumalan palvelijoita maailman rakentamisessa, loiko heidät Jumala välittömästi vai kuka?

Menocchio: Luonto sai ne aikaan maailman täydellisimmästä substanssista, samoin kuin juustosta syntyy matoja, mutta ulos tullessaan ne saavat tahdon, älyn ja muistin Jumalalta, joka siunaa ne. (s. 118.)

Menocchion inkvisitiokuulustelun merkilliset tallenteet kiinnittivät Carlo Ginzburgin huomion hänen kartoittaessaan 1960-luvulla inkvisition kerettiläisyystulkintoja. Ginzburg palasi aineiston pariin myöhemmin ja kirjoitti sen pohjalta tässä käsiteltävän kirjan. Kirjassa pohditaan, mistä Menocchion omintakeiset ajatukset saattoivat olla peräisin ja kuinka kirkko voi kokea vanhan myllärin horinat uhaksi oikeauskoisuudelle. Menocchion älyllinen individualismi pääsee arvoonsa.

Kirja on metodisesti lähiluvun ('hitaan lukemisen") ja laajan lähteistönhallinnan ylistystä. Sen kiinnostavinta antia on pohdiskelu kansankäsitysten näkyvyydestä vallanpitäjien teksteissä ja siitä, kuinka ruohonjuuritason ilmiöt ja yhteiskunnalliset suuret linjat liittyvät toisiinsa. Matti Peltonen $(1999,55)$ on kuvannut Ginzburgin esitystapaa kirjassa: "Pitkän keston rakenteiden esittäminen lyhytaikaisten tapahtumien kanssa luo jännittäviä konflikteja, joiden kuvaamisella myös lukijan mielenkiinto tutkimuksen edetessä pidetään vireänä.” Metodologisissa pohdinnoissaan Ginzburg 


\section{KESKIAJAN LOPPU JA YKSI HULLU MYLL̈̈RI}

on osuva, joskin niukkasanainen. Kirja on saavuttanut vakiintuneen aseman mikrohistorian ja mentaliteettitutkimuksen alueilla.

\section{KeSKIAJAN LUKEMINEN}

Kirja etenee useammalla tasolla samanaikaisesti: Ensinnäkin se kertoo mylläri Menocchiolle kohtalokkaaksi koituvan inkvisitiotutkimuksen kulusta elävästi ja seikkaperäisesti yksityiskohtaisten kuulustelupöytäkirjojen pohjalta. Myöhemmin Ginzburg (1996, 182) on kirjoittanut, että Juusto ja madot "ei rajoitu vain rekonstruoimaan yksilöllistä tapahtumaa - se kertoo sen". Toisekseen Ginzburg erittelee kirjassa maailmankuvaa sitä mukaa kuin kuulustelut sitä valottavat. Inkvisitiokuulustelujen pyrkimyksenä oli saada mahdollisimman täydellinen käsitys Menocchion harhaoppisesta maailmankuvasta. Kolmannekseen kirjassa käsitellään lähteitä, joista Menocchion ajatukset juonsivat juurensa. Ginzburg pyrkii paitsi jäljittämään lähteitä myös ymmärtämään tapaa, jolla Menocchio lähteitä tulkitsi.

Carlo Ginzburg käyttää keskiaikaisia kirjallisia lähteitään erittäin yksityiskohtaisesti. Hän löytää niiden välille yhteyksiä, jotka monesti kertovat enemmän kuin lähteet yksinään. Hän lukee lähteitään erittäin huolellisesti ja tekee inkvisitiopöytäkirjojen merkinnöistä tulkintoja, jotka kurottavat lausunnonantajien tarkoitusperiin, käsityksiin ja maailmankuvaan. Ginzburg eläytyy niin syyttäjän kuin syytetynkin ajatusmaailmaan. Menocchion ajatusten takana olevat aikalaisskeemat on käsitelty kirjassa perusteellisesti, joskin melko suorasukaisesti ja kyseenalaistamatta. Paikoin Ginzburg tekee lähteistään rohkeita päätelmiä, jopa poleemiseen sävyyn.

Ginzburg viittaa toistamiseen "talonpoikaiseen maailmankuvaan" Menocchion ajatusmaailman selittäjänä, mutta ei pohdi sen olemusta sen yksityiskohtaisemmin saati ala hahmotella sen kokonaisuutta. Ginzburg esittää kuitenkin muutamia yksittäisiä kiinnostavia vertailevia mytologisia pohdiskeluja: talonpoikaisen maailmankuvan juuret ovat syvällä, mikä ilmenee kaukaisten kulttuurien vastaavankaltaisissa maailmankuvan elementeissä. Toistuvasti Ginzburg määrittää talonpoikaisuskonnon materialismiksi, käytänteiden eli rituaalien seuraamiseksi, vastakohtanaan kirjauskontojen pyrkimys systemaattisuuteen. Toiseksi talonpoikaisuskonnon keskeiseksi piirteeksi nousee suvaitseva panteismi. Ginzburgin (s. 127) mukaan "Menocchio pyrki ilmaisemaan maaseudun asukkaiden sukupolvia vanhaa, vaistonvaraista perusmaterialismia käyttämällä kristinopin, uusplatonismin ja skolastisen filosofian kyllästämää termistöä”. Talonpoikainen maailmankuva oli silti vain yksi elementti, jonka varaan Menocchion näkemykset rakentuivat.

Kirjassa käytellään lähteitä monipuolisesti tulkiten ja lähdeaineisto osoittaa Ginzburgin tuntevan laajalti 1500-luvun uskonnollisen murroskauden henkiset vaikuttajat. Menocchio osasi lukea, ja hän luki keskeisimmät kirkon kieltämät kirjat - Decameronen, Koraanin, Fioretto della Bibbian. Kirjojen ohella talonpoikaiskulttuuri, katolinen kasvatus ja värikäs asiakaspiiri muovasivat Menocchion maailmankuvan erilaisten käsitysten kudelmaksi, joka ei ollut lainkaan vedenpitävä eikä ristiriidaton, 
JOONAS AHOLA

mikä inkvisition oli helppo osoittaa. Menocchion omintakeiset tulkinnat ovat osoituksia lukijan vallasta tekstiin.

Juusto ja madot etenee siis Menocchion inkvisitiokuulustelujen mukaisesti eikä teemoittain. Joka toisessa luvussa Ginzburg käsittelee aineistosta nousseita asioita yleisemmällä, teoreettisemmalla tasolla. Aiheen käsittely toisaalta syvenee, toisaalta hajaantuu, ja luvut toimivat lähes itsenäisesti, kun temaattinen rakenne etenee kuin tajunnanvirta. Ginzburg kykenee tuomaan esiin, että maailmankuva ei ole irrallaan ihmisestä, vaan seuraa ihmistä ja muuntuu muutoksissa ja uhkaavissa tilanteissa. Rakenne antaa teokselle inhimillisen sävyn, mutta temaattinen sekavuus ei ole tutkimuskirjan avu. Ilmeisen taiteellisin intentioin laadittu sisällysluettelo ei auta avainasioiden löytämisessä. Kirja on tarkoitettu luettavaksi kokonaisuutena.

\section{KLASSIKON ASEMAAN}

Ginzburgin teos on ollut innoittaja ja esikuva monille keskiaikaisten lähteiden uudelleentulkitsijoille. Hiljattain suomennetuista tutkimuksista mainittakoon eräiden keskiaikaisten tapahtumien seikkaperäiseen mikrohistorialliseen rekonstruktioon pyrkinyt Natalie Zemon Davisin teos Martin Guerren paluu (2001, alkuteos 1982) ja Robert Bartlettin teos Hirtetty mies (2006, alkuteos 2004). Gaudeamus-kustantamon panos keskiajan mikrohistoriallisen tutkimuksen kääntämiseen on viime vuosina ollut huomattava. Keskiaikaisen maailmankuvan tulkitsijoista esimerkiksi Jacques Le Goff (1980, xiv) mainitsee Carlo Ginzburgin lähdekriittisen lukutavan keinoksi hahmottaa keskiaikaisia kansankäsityksiä. Professori Matti Peltosen suomennokseen kirjoittama esipuhe johdattaa hyvin teoksen merkitykseen myöhemmässä historiantutkimuksessa.

Carlo Ginzburg rakentaa lähteiden pohjalta kertomuksen, jossa nousevat näkyviin yhteydet kansanuskomusten ja yhteiskunnallisten valtarakenteiden välillä. Hän löytää lähteistä yksityiskohtia, joita selittämällä tulee haastaneeksi vakiintuneita historiakäsityksiä. Hän tulkitsee pienistä vihjeistä yksityiskohtia, joissa näkee suuria linjoja. (ks. myös Ginzburg 1996, 73-76.) Juusto ja madot laajensi historiallisesti merkityksellisen yksilön käsitteen kattamaan eliitin edustajien ohella myös massojen edustajan. Mylläri Menocchio halusi aikanaan ajatuksilleen oppineen yleisön, ja kun hän sen inkvisitiotuomareissa sai, hän päätyi roviolle. Ginzburgin kirjassa hänen ajatuksensa saavuttavat lopulta kiitollisen yleisön ja kuolemattomuuden.

\section{KirJallisuUS}

BARTLETT, ROBERT 2006: Hirtetty mies: kertomus ibmeestä, muistista ja kolonialismista keskiajalla. Helsinki: Gaudeamus.

DAVIS, NATALIE ZEMON 2001: Martin Guerren paluu. Helsinki: Gaudeamus. 


\section{KESKIAJAN LOPPU JA YKSI HULLU MYLL̈̈RI}

GINZBURG, CARLO 1996: Johtolankoja. Kirjoituksia mikrohistoriasta ja historiallisesta metodista. Helsinki: Gaudeamus.

LE GOFF, JACQUES 1980: Time, Work and Culture in the Middle Ages. Chicago: The University of Chicago Press.

PELTONEN, MATTI 1999: Mikrohistoriasta. Helsinki: Gaudeamus.

Filosofian lisensiaatti Joonas Ahola on folkloristiikan jatko-opiskelija Helsingin yliopistossa. 